\title{
Ideal de mujer virtuosa \\ Instruida, sencilla, señora de la casa, pozo de dulzura y abnegación. Rastreos sobre la educación de la mujer a finales del siglo XIX y principios del siglo $\mathrm{XX}^{1}$
}

DEAL FOR VIRTUOUS WOMAN - EDUCATED, SIMPLE, LADY OF THE HOUSE, WELL OF SWEETNESS AND DEVOTION. TRACES ON THE EDUCATION OF WOMEN IN THE LATE XIX AND EARLY XX

IDEAL PARA A MULHER VIRTUOSA - EDUCADO, SIMPLES, DONA DA CASA, BEM DE DOÇURA E DEVOÇÃO. TRAÇOS NA EDUCAÇÃO DAS MULHERES NO FINAL DO SÉCULO XIX E INÍCIO DO SÉCULO XX

\section{Carold Andrea Hernández Gómez+ / andidi22@hotmail.com}

\begin{abstract}
Resumen
Los trazos inscritos en la educación femenina a finales del siglo XIX y comienzos del XX, fueron atravesados por intereses económicos, políticos, culturales, educativos y pedagógicos, que pusieron a circular unos saberes (economía doméstica, menaje, costura y zurcido, urbanidad, higiene...) y que a su vez dieron paso a un tipo ideal de mujer "virtuosa", enmarcado en un deber "natural" de ser madre y esposa. Para lograr este ideal se desplegaron ciertas prácticas disciplinarias que buscaron encauzar los sentimientos y deberes de las niñas; uno de los escenarios propicios para alimentar esta formación fue la escuela de niñas.
\end{abstract}

Sin embargo, aquellas que atentaban contra la moral y las buenas costumbres de la época (las meretrices, las obreras, las que promulgaban doctrinas feministas y las madres egoístas) estaban desprovistas de cualquier signo de amor y admiración; sus conductas eran reprobadas y sus prácticas silenciadas. Más bien tenían ese tinte de Eva, causante de la perdición del paraíso.

\section{Summary}

The lines inscribed on female education in the late nineteenth century and early twentieth centuries were crossed, that began to circulate about knowledge (housekeeping, household, sewing and mending, manners, hygiene economic, political, cultural, educational and teaching interests... ) and that in turn gave way to an ideal type of woman $>><<$ virtuous framed in a "natural" must be a mother and wife. To achieve this ideal certain disciplinary practices that sought to channel the feelings and duties of girls were deployed; one of the auspicious scenarios this training was to feed the girls' school.

However, those who sought the moral and good customs of the time (the prostitutes, workers, feminists who promulgated the doctrines and selfish mothers) were devoid of any sign of love and admiration; disapproved behaviors were silenced and their practices. Rather dye that Eva had caused the destruction of paradise.

Resumo

Os traços matriculados no ensino feminina no século XIX e início do século XX, foram cruzados por interesses econômicos, políticos, culturais, educacionais e de ensino, e colocado em circulação algum conhecimento (housekeeping, cozinha, costura e remendar, civilidade, higiene ...) e que por sua vez deu lugar a um tipo ideal de mulher "virtuosa", situado em um direito "natural" de ser mãe e mulher. Para atingir este certas práticas disciplinares ideais que buscaram a canalizar os sentimentos e deveres de meninas foram mobilizados; um dos cenários para a alimentação deste treinamento foi a escola das meninas.

No entanto, aqueles que ameaçava a moral e os costumes da época (as prostitutas, os trabalhadores, as doutrinas feministas promulgadas e mães egoístas) eram desprovidos de qualquer sinal de amor e admiração; foram reprovados comportamentos e práticas silenciadas. Em vez teve que tinge de Eva, causando a destruição do paraíso.
Palabras clave

Mujer, educación femenina, saberes, amor, ideal de feminidad.

\section{Fecha de recepción: 30 de junio de 2014 / Fecha de aceptación: 31 de octubre de 2014}

\footnotetext{
* Estudiante de Licenciatura en Psicología y Pedagogía, Monitora de investigación en el curso "Educar los sentimientos: discursos en torno al amor y la mujer en la educación en Colombia (final S. XIX - comienzo S. XX) 2013-II/2014.
} 
1 El presente documento es producto de la reflexión suscitada en la participación de los espacios del semillero de investigación, los encuentros en el SPI y las aproximaciones que surgieron en el proyecto "Educar los sentimientos: discursos en torno al amor y la mujer en la educación en Colombia (final S. XIX - comienzo S. XX)", coordinado por las profesoras Ximena Herrera y Carolina Ojeda.

\section{Introducción}

Las prácticas educativas y pedagógicas configuradas a finales del siglo XIX y comienzos del XX, entraron en conexión con fuerzas sociales, económicas, políticas y culturales que demarcaron un espacio femenino (privado) y un espacio masculino (público). En ellos se desplegaron distintas prácticas que forjaron la construcción de subjetividades, tanto femeninas como masculinas.

En cuanto a lo femenino, los discursos que circularon se basaban en una condición "natural", delimitando valores, cualidades, virtudes, comportamientos o costumbres que debía tener el "bello sexo". La condición femenina quedó ligada a un destino primordial de ser madre y esposa, en aras de un bienestar social y moral de la sociedad. Además, la devoción y virtud que debía encarnar la mujer debía desarrollarse desde muy tierna edad y potenciarse gradualmente, con el fin de lograr a futuro esposas agradables, dóciles, compasivas y buenas, dedicadas al hogar y al cuidado de los hijos.

"[...] que tengan paciencia con los pobres y los enfermos; que presten a éstos los auxilios que les sea buenamente posible; que las niñas comprendan que esta es la más hermosa de las virtudes, la más propia de la mujer y se acostumbre a cuidar a su casa y a amar a los suyos para que en ella reine la paz y la alegría" (Dirección del Secretario de Instrucción pública, 1899, pp. 52-53).

En este sentido, es importante problematizar y visibilizar cómo las prácticas educativas entraron a orientar y establecer unos modos aceptados de ser y formarse como mujer; haciendo circular saberes como: la economía doméstica, la higiene general, las bellas artes, costura, contabilidad doméstica, urbanidad, cocina, zurcido, modistería, al igual que la moral, el cuidado, las buenas costumbres, entre otros, con el fin de educar y conducir la naturaleza femenina. Ejemplo de esto, son las lecciones y la distribución del tiempo de trabajo en una Escuela de niñas:

“Martes: Mañana, Rezo-Corte y preparación de prendas-dictado: un tema de Economía doméstica-Recreo-Aritmética-Ejercicios prácticos-Recreo-Geografía en el jardín.

Tarde: Lectura en alta voz y explicación de lo leído-Conversación sobre religión-conversación sobre los deberes de la mujer animada con historias y ejemplos-Recreo-Conversación sobre algún tema de Economía doméstica" (Dirección del Secretario de Instrucción pública, 1899, pp. 43-44).

Viendo lo anterior, y a partir de la perspectiva arqueológica-genealógica propuesta por Foucault ${ }^{1}$, se realizó un rastreo de documentos a partir de distintas fuentes, en este caso, publicaciones del IDEP2 y de los Hermanos Cristianos de la Salle. De esta forma se buscó dar una mirada a la historia, no desde una linealidad cargada de discursos hegemónicos o de relaciones causa-efecto; sino buscando problematizar los juegos de verdad y las relaciones saber/poder que giraron alrededor del cuerpo femenino y los modos de ser y construirse como mujer-mujeres, así como del estatuto del amor y el ideal de feminidad.

\section{Mujercita dulce y buena}

"Así si queremos que las niñas tengan maneras dulces, agradables y distinguidas, al mismo tiempo que se las enseñamos, debemos elevar su espíritu y ennoblecer su corazón".

Del Real y Mijares, 1908.

1 El grupo Historia de la Práctica Pedagógica en Colombia (GHPP), fundado por Olga Lucía Zuluaga, utilizó como caja de herramientas el enfoque foucaultiano para historizar la pedagogía en Colombia; a su vez, elaboró nuevas categorías y nociones metodológicas parar mostrar, tanto la historicidad de la pedagogía, como el papel del maestro y la escuela a nivel político, cultural y social.

2 Entre ellas se toman las revistas: El Maestro de Escuela, Revista de instrucción pública, La Escuela Normal y Repertorio escolar. 
Para formar aquella mujer virtuosa, devota y fiel que preservará el honor de la familia, se debían cultivar ciertas cualidades, pero además silenciar y reprimir otras. La configuración del sujeto femenino se caracterizó por su sometimiento a sacrificios y deberes que implicaban moldear las predisposiciones y peligros que representaba, tales como: despertar el fuego pasional, conllevar a la seducción, corromper el alma del hombre y desviar los designios naturales. Por lo ello, tanto los preceptos morales como los saberes que circularon dentro y fuera de la escuela, buscaban educarla para el hogar, convertirla en esposa, madre virtuosa y ejemplar.

"[...] a la mujer en especial vuelve los ojos la escuela moderna, para que pueda en su día embellecer la existencia en su humilde hogar, y aparte así al padre, al esposo, a los hijos, del bodegón y de la taberna, esos horribles antros que consumen a un tiempo la salud, la felicidad y el pan de la familia obrera" (Dirección del Secretario de Instrucción pública, 1899, p. 1).

La escuela de niñas se situó entonces como el lugar propicio para que, a través de una instrucción adecuada, se lograra materializar a la mujer imaginada con una educación propia de su sexo. Sin embargo, no sólo la escuela tuvo en sus manos la formación y dirección de la educación femenina, también coexistieron con ella otras instituciones encargadas de estas prácticas, como la iglesia y la familia, por medio de consejos de madres y abuelas, las empresas o fábricas, los barrios entre otros. Esta confluencia de escenarios buscaba acentuar el lugar y rol de las mujeres en la sociedad: como madres, portadoras y forjadoras de una gran nación y como las encargadas de brindar paz y regeneración física y moral; por consiguiente, la educación que recibían tenía que estar a la altura de esa misión. Así lo señalaban varios fragmentos que circularon en la Revista pedagógica de 1935 y en la Revista de Instrucción Pública de 1894

"Una mujer instruida es un tesoro para un hombre, es una dicha para un hogar, es un ángel para sus hijos" (Menéndez, 1894).

"Como mujer además de madre, ejerce también la más noble misión en el seno de la familia y de la humanidad. Misión de paz, de regeneración física y moral, de felicidad y concordia" (Gómez Anzola, 1935).
Igualmente, en los tratados de educación como la Didáctica Magna y el Emilio de Rousseau, se resaltaban apartados dedicados a la educación de la mujer. Una educación orientada por la naturaleza y los designios del Creador, donde las buenas costumbres, la docilidad, la paciencia, la resignación y el excelente comportamiento eran importantes para hacer de la mujer una digna esposa y compañera del hombre. Así lo ilustra Menéndez (1894): "La mujer instruida es la inteligente compañera de su marido; ella lo comprende, vive de sus ideas y se eleva con él por encima de los prosaicos quehaceres domésticos" (p. 111).

Se procuraba que la condición femenina estuviera en función de otros "esposo, hijos, hogar, familia, discípulos" y cualquier aire de ignominia, mal genio, falta de pudor o desacato de las virtudes morales, debía ser reprobado al instante, siendo necesario someter desde la infancia esos atributos nefastos en la mujer. Como lo expresa Restrepo Mejía (1916), en sus apartados de "Pedagogía doméstica": "En la mujer el mal carácter es más repugnante que en el hombre, porque nosotros no la concebimos a ella sino como un pozo de dulzura y abnegación" (p. 307). En concordancia con lo anterior, Del Real y Mijares (1907), anota en su escrito sobre la Escuela de niñas, que es necesario que:
"[...] la niña aprenda desde la escuela a ser económica, laboriosa, digna, pura en sus pen- samientos, palabras y obras, dulce, cariñosa e indulgente, y que sepa sacrificar sus gustos y sus deseos a los gustos de los demás, cifrando su dicha en hacer buenos y felices a los que la rodean" (p. 269).

El ideal de mujer debía identificarse con la imagen de María, abnegada, madre y compañera solícita; adicionalmente debía estar siempre dispuesta a agradar al marido, procurar ser hermosa y simpática, ser su consuelo contra la dura jornada, atenta a sus requerimientos y escucharlo con especial atención. "Por él y sólo para agradarle a él, cuidareis de vuestros hechizos, [...] de que os pueda considerar siempre como el más bello adorno de su casa" (Restrepo, 1916, p. 306).

Del mismo modo, su principal misión y tarea era "ser madre", pues sobre sus hombros estaba el velar por el bienestar y futuro de sus hijos; debía ser la primera 
educadora e imprimir en los niños la moral cristiana, los conocimientos usuales y esa lactancia moral: "su gran responsabilidad y su dignísimo oficio" se inscribía en la maternidad.

"La Pedagogía Doméstica otorga a la madre el lugar más importante en la formación del niño. Ella es su primer apoyo y su más solícita maestra; sobre la tierra es el primero y el último de sus amores; ella tiene una secreta virtud, una unción divina para guiar a su hijo por la senda del bien" (Gómez Anzola, 1935, p. 126).

Por lo tanto, como señaló Pestalozzi (1893), se requería de una educación completa y extensa que brindara a la madre la oportunidad de formarse y lograr una guía clara en su inteligencia que fuera complemento de su instinto maternal.

"La madre tiene un poder casi ilimitado sobre su hijo, durante los primeros años de éste, y en la niñez se forman los hábitos que más influyen en la vida; es pues de la mayor importancia que en tal período se repriman las propensiones egoístas y se estimulen todos los buenos impulsos. A la verdad, una niñez descuidada o mal dirigida por parte de la madre, jamás podrá ser corregida por una educación subsiguiente" (Pestalozzi, citado en Johonnot, 1893, p. 276).

En este sentido, las prácticas provenientes de diferentes instancias operaron como un dispositivo que demarcó la educación femenina y el deber asignado a la mujer. Sin embargo, las prácticas educativas no sólo se ejercían sobre ellas. Las mujeres como institutoras o maestras, madres y esposas, ejercían prácticas de afecto $^{3}$ sobre sí mismas y sobre los demás: "Es institutora cuyas lecciones jamás se olvidan, aún cuando la muerte haya cerrado ya los labios que las daban. Es quien enseña la ternura sin hablar de ella al prodigarla" (Simón, 1983).

3 Esta noción de afecto no solo responde al concepto de ternura o niñez, sino que está relacionada con la posibilidad de afectar a sí mismo y al otro. Asumiendo el afecto como prácticas de poder y resistencia.

\section{El "bello sexo", la literatura y el amor}

"El hombre es fuego.

La mujer estopa.

Viene el diablo y sopla".

Freyle Rodríguez

Los sentimientos se definieron como distintos estados del alma que deseaban habitualmente una cosa y no privaban al alma de su serenidad y libertad (Del corazón y la sensibilidad humana, 1894). Esta noción fue configurada por los preceptos morales y religiosos de la época: por un lado, la compasión, la caridad cristiana, la abnegación y la templanza, se catalogaron como sentimientos piadosos (Inclinaciones buenas); mientras que, por otro lado, la pasión, la gula y el orgullo se asumieron como afecciones excesivas o violentas que pervertían el alma. Sentimientos como el amor dependían de la dirección que se les diera. Es decir que el contenido emocional se entrelazaba con las conductas, discursos y valores culturales que circulaban para esta época.

No obstante, en la mujer el amor debía ser regulado desde la niñez, pues en ella imperaba la pasión, el histerismo y la debilidad. Así se manifiesta en los fragmentos del Doctor del Valle Atiles, F. (1893) en el tratado sobre Higiene de la inteligencia:

"La niña trae consigo una organización distinta, y además aporta un legado de predisposiciones morbosas físicas y de predisposiciones morales e intelectuales, contra las cuales la educación tiene que luchar [...] el histerismo en el bello sexo; no ese que se traduce en ataques, sino todas esas manifestaciones que al histérico se pueden reducir después de un atento examen y que comprometen la felicidad de la familia" (Doctor del Valle, 1893, p. 319).

Por eso, las prácticas educativas que se ejercían sobre ella, y que moldearon su cuerpo, actuaban como mecanismos para encauzar sus sentimientos y fortalecer la educación moral que fomentara su instinto maternal. 
Era una educación preventiva y represiva que partía del supuesto del mal y la desconfianza; que tendía a impedir las transgresiones de la moral sexual para que la mujer no pudiera dañar o atentar contra los fines sociales y el bienestar de la sociedad.

De acuerdo a esto, debía constituirse una educación diferenciada del hombre, puesto que en él se contemplaba un postulado optimista y de fe en la perfectibilidad de la naturaleza humana. Por consiguiente, las prácticas desde la educación física, la educación intelectual, la educación del sentimiento y la educación estética, se ejercían de forma distinta para cada sexo y en función del puesto que ocupaba cada uno en la sociedad.

En cuanto al "bello sexo", la Escuela de niñas puso en circulación asignaturas y programas como: higiene, menaje, primeros auxilios, contabilidad doméstica, trabajos caseros, zurcido y dibujo; saberes desde luego orientados hacia un amor a Dios, al prójimo, a la familia y a los niños. Sentimientos tiernos y delicados que se asumían como intrínsecos en el espíritu femenino.

"El amor al prójimo ha de ser el sentimiento que dirija las obras de misericordia, así debemos decir a las niñas que es preciso amar a todas las personas sin excepción porque todas son nuestros prójimos, nuestros semejantes" (Del Real y Mijares, 1907, p. 261).

No obstante, el amor conyugal se daba de forma cautelar, pues el exceso de amor, o la desmedida en el mismo, acarrearía serias consecuencias que pondrían a tambalear el honor de la familia. Una de estas precauciones conllevó a que las mujeres estuvieran al margen durante años de la posibilidad de ejercer la lectura y la escritura, por el miedo de que empezaran a intercambiar versos de amor con sus novios o algún mocetón que las pretendiera. A su vez, se buscaba frenar la imaginación descarnada que atentara contra el pudor o incitara a hechos vulgares. En palabras de Vahos (2002): "[...] la mujer deberá frenar sus sentimientos e imaginación, evitando todo lo que la fomentase, como conversaciones, amistades, lectura y la ociosidad" (p. 17).

Sin embargo, esa idea comenzó a transformarse gradualmente, pues la literatura, a través de la poesía, la fábula, las novelas, los discursos, los versos y los periódicos, se situó como un medio para ejercer y recrear prácticas que reflejaban las costumbres de la época. Igualmente, construyó una imagen femenina a partir de la moral cristiana y alentó un "espíritu romántico" en el que el amor fue adquiriendo otras significaciones. Ejemplo de esto, se evidencia en la fábula de Andrés Bello (1872) "La ardilla, el dogo y el zorro" (fábula para el álbum de una hija).

"Madame ardilla con un dogo fiero compadre antiguo suyo y compañero, Salió al campo una tarde a solazarse. Entretenidos iban en gustosa conversación, y hubieron de alejarse

Tanto que encapotada y tempestuosa los sorprendió la noche a gran distancia de su común estancia.

Bella señora mía,

vuestra merced perdóneme le decía si interrumpo su plácido reposo después de tanto afán cuando el consuelo

[Dejando como moraleja para

las hijas tres importantes cosas:]

De un seductor las artes alevosas

De la maldad el triste paradero

y lo que vale entonces de la vida

la acertada elección de un compañero" (p. 160).

A través de fábulas como la anterior, se alimentaba un espíritu sensible, prudente y fiel. A su vez, se ilustraban las consecuencias que acarreaba no elegir bien al futuro esposo y dejarse convencer o atrapar por palabras dulces, regalos o promesas de posibles seductores.

Los escritos también dieron a la mujer la posibilidad de expresar sus sentimientos, aunque siempre encaminados por el "deber ser" que se imponían sobre ella. Como el discurso "La obra de la mujer", proferido por una alumna y dedicado al señor Eustorijio Salgar

\section{"XIV}

Que a donde la ley no llega

llegue el amor ilustrado

que no sólo llora y ruega,

sino que también deniega

sus glorias al depravado. 


\section{XVI}

El amor bien entendido

podrá en las débiles manos

de nuestro sexo abatido,

hacer cuanto no han podido" (p. 360).

La literatura adquirió connotaciones particulares; saberes y prácticas circularon por medio de la lectura, la escritura, la poesía y las fábulas, las cuales visibilizaron los modos de afirmación de lo femenino. Así mismo, el poder de los textos naturalizó un discurso encaminado a las características propias de la feminidad: doncellez, pureza, esposa hacendosa (Rodríguez, 1997); conjuntamente, la maternidad y el matrimonio se convierten en los escenarios de circulación del amor, en los que la mujer se define mediante la atención a las necesidades de los otros (hijos y esposo). Su amor, es un amor maternal y contenido a nivel pasional. Su emotividad desbordada fue conducida mediante prácticas de disciplinamiento, sustentadas desde saberes como la medicina, la psicología, la educación física, la moral, la economía doméstica, la urbanidad y la literatura.

\section{Aquellas... "encarnación de Eva"}

"Encarnación de Eva, causa de todo mal, y debiendo aborrecer el cuerpo con sus necesidades y apetitos carnales, despreciaba a la mujer que le personificaba la tentación".

Wihelmi de Dávila.

Manuales, prohibiciones, reglamentos, regímenes..., denotaban claramente los valores culturales y el poder moralizador de instituciones como la iglesia, la escuela y la familia. La organización social articulada en la época, promulgaba sancionar el descarado libertinaje y cualquier aire de degradación que atentara contra la institución familiar y el bienestar de la sociedad.

En este contexto, la mujer fue uno de los pilares para salvaguardar las buenas costumbres, siendo ejemplo de devoción y castidad, debía formarse como una mujer ideal, no vulgar, ni ignorante. Igualmente, tenía que cultivar en sus hijos cualidades de respeto, honestidad, amor por la patria y la moral cristiana y, como maestras, su conducta también tenía que ser intachable.

Sin embargo, se fueron hilando otros trazos alrededor de mujeres que representaban la causa del deshonor familiar, la vergüenza de la sociedad, la semejanza de la tentación; todas ellas, las madres egoístas, las meretrices, las cantoneras, las que abandonaban el hogar y aquellas que promulgaban doctrinas feministas, recibieron censuras, reprobaciones y se veían con desagrado y desdén.

Ejemplo de esto, se muestra en textos como "La institución de la mujer cristiana" de Luis Vives y la "Perfecta casada" de Fray Luis de León, autores que lanzan reprobaciones contra las mujeres que salen y hacen vida activa: "[...] las ponen que no hay por dónde cogerlas de andariegas, desvergonzadas y semejantes a las públicas cortesanas y cantoneras" (Pardo Bazah, 1894, p. 286). Pues la prostitución y las pasiones descarnadas, además de rechazarse y reprimirse, se veían como un claro atentado contra la moral y la virtud; el grito obsceno y las manifestaciones excesivas eran claramente censuradas; el amor debía ser más disciplinado y los sentimientos de ternura no podían pertenecer a las prostitutas o aquellas que desbordaban apetitos carnales.

A su vez, la separación de la mujer del hogar, unas por el empuje que iba tomando forma con las doctrinas feministas $y$, otras, por el aumento de oportunidades de trabajo en las fábricas y en otros lugares, se dilucidó como un grave problema que amenazaba incesantemente la constitución del hogar. Por eso se buscaba prohibir el trabajo en las fábricas para las mujeres casadas. Al respecto, en el artículo "De la influencia de la mujer y de su educación en las costumbres" que circuló en 1893, se mencionaba lo siguiente:

"[...] procurar a las mujeres un empleo útil para sus facultades en el interior de la casa. Independientemente de las nuevas industrias que una educación bien dirigida puede poner a su alcance, hay una muy antigua, respetable entre todas y verdaderamente ventajosa, bajo el punto de vista económico: la industria de madre de familia, que estamos dejando perder" (Simón, 1983, p. 427). 


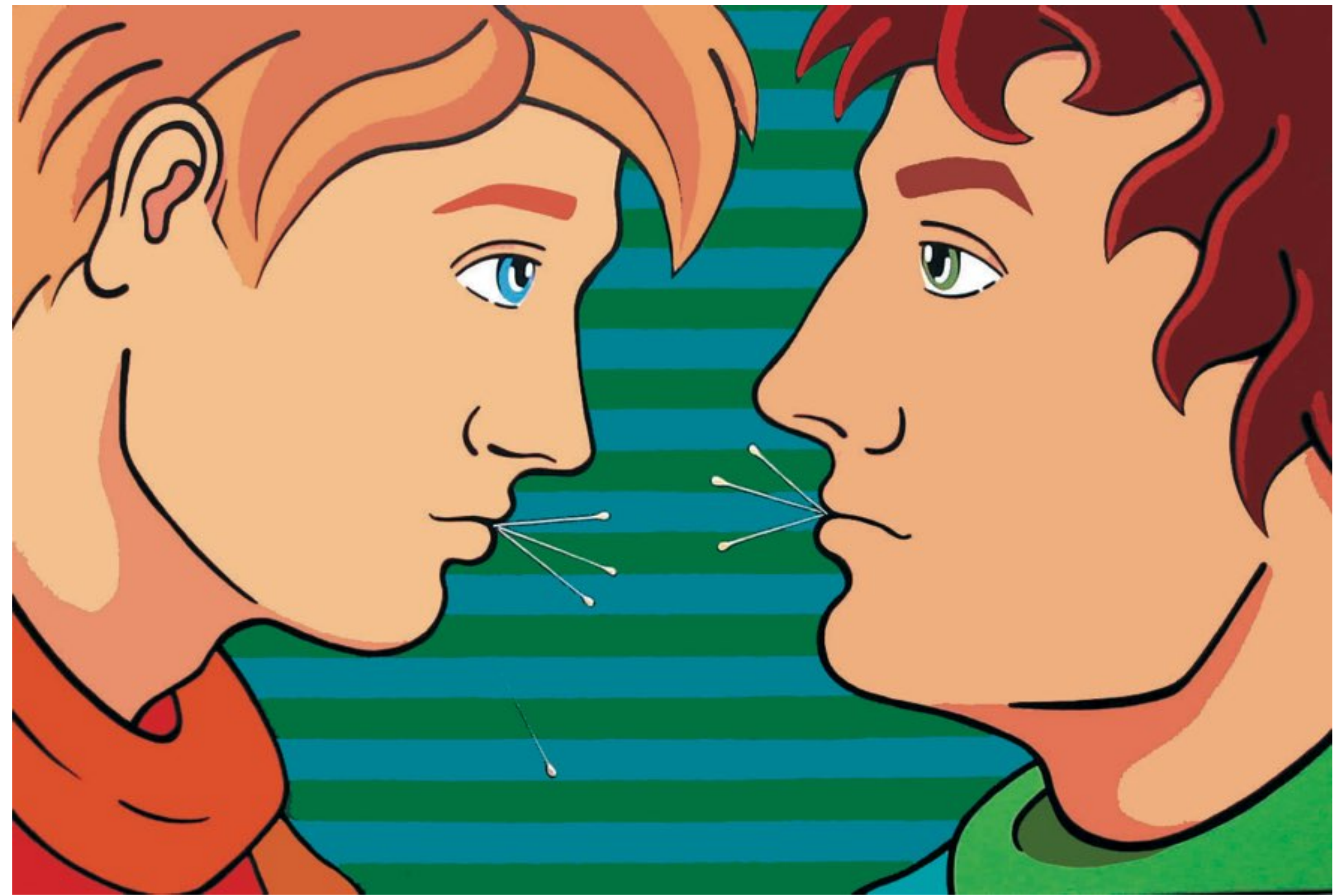

Franklin Aguirre ॥ Título: Siete Alfileres ॥ Técnica: Acrílico sobre lienzo ॥ Tamaño: 113 X 169 cm ॥ Año: 2002 
Con opiniones como la anterior, se buscaba tomar medidas para contrarrestar lo que estaba sucediendo con el trabajo de la mujer fuera de casa. Pero aún así el ideal de mujer virtuosa se desvanecía con mujeres que no estaban dedicadas a su esposo, a sus hijos y el hogar. Las madres, que se esmeraban más por su belleza y cuidado físico y que entregaban al recién nacido a manos "mercenarias" para alimentación y primeras enseñanzas, eran catalogadas como madres egoístas, malas madres que desconocían lo elevado de su misión.

"A esta clase de madres no les importa nada el porvenir, físico, moral e intelectual de sus hijos. El egoísmo las hincha y las domina, y en cambio de no tener una arruga más en su cuidada frente o un cabello blanco entre los rizos de su cabeza, exponen a sus pequeños hijos a ser víctimas más tarde de enfermedades dolorosas y vergonzosas, a pervertir sus nobles sentimientos, a llenarse de faltas y de malas costumbres, y lo que es peor a mancillar su inocencia dejando echar los primeros cimientos del vicio en el alma inmaculada del pequeñuelo" (Dirección del Secretario de Instrucción Pública, 1899, p. 91).

Aquellas que se salían del ideal de mujer virtuosa, debían ser excluidas de cualquier aire de amor y admiración. Se veían como las que amenazaban la constitución del hogar, el bienestar y felicidad de la nación.

\section{Consideraciones finales}

Las prácticas que se tejieron sobre la educación femenina y el rol que debía desempeñar la mujer en el seno de la sociedad, fueron articulando construcciones y estrategias que actuaron en su cuerpo, subjetividad, en los modos decibles de nombrarla y en los oficios o profesiones que podían ejercer. A su vez, las virtudes morales y sociales cobraron un valor importante en la formación femenina. La escuela se constituyó en uno de los escenarios que debía forjar y potenciar la construcción de una mujer virtuosa, instruida, sumisa y devota; alejada de cualquier quebranto contra la moral pública.

Por consiguiente, los trazos que se fueron hilando muestran una mujer como ama de casa, esposa y madre, al igual que la primera maestra moral de sus hijos. Por lo tanto, educarla resultaba útil para lograr un ideal de feminidad: mujer virtuosa solícita, abnegada, buena, Ilena de castidad y obediencia, que hiciera los mayores esfuerzos por merecer y ganar el amor de su esposo y la aprobación de la sociedad.

Ahora bien, en la educación muchos de estos discursos han construido una serie de imaginarios que reproducen una cultura y unos patrones en torno a la mujer y al amor. Ligando muchas veces el constructo de mujer con el de maternidad, ternura, docilidad, amor, cuidado. No obstante, la configuración de lo femenino va más allá de estos caracteres y ha pasado por una serie de cambios y transformaciones desde las últimas épocas; transformaciones que han dejado huellas indelebles que repercuten de una u otra manera en los movimientos y cambios actuales.

Finalmente, este trabajo se constituye como un aporte que muestra las tensiones, resistencias, intereses y prácticas que configuraron las subjetividades femeninas $y$ que desplegaron un dispositivo pedagógico y educativo enmarcado en saberes como la literatura, la economía doméstica, las buenas costumbres, la cocina entre otros, con el fin de formar una mujer dulce y buena que alimentara la regeneración física y moral en favor del bienestar de la sociedad. 
Bello, A. (1872). La ardilla, el dogo y el zorro. (fábula para el álbum de una hija). La Escuela Normal, Periódico oficial de Instrucción pública. T. III, p. 160.

Del corazón y la sensibilidad humana. (1894. ). Revista de la Instrucción pública de Colombia. Año 2, T. III, p. 167.

Del Real y Mijares, M. (1906). Sección pedagógica. Escuela de Niñas. Revista de la Instrucción pública de Colombia. Tomo $\mathrm{XX}, \mathrm{p} .84$.

Del Real y Mijares, M. (1907). Escuela de niñas. La Instrucción en las Escuelas de niñas. Revista de la Instrucción pública de Colombia. T. XXI, p. 261.

Del Real y Mijares, M. (1908). Escuela de niñas. La instrucción en la Escuela de niñas. Revista de la Instrucción pública de Colombia. T. XXIII, p. 97.

Dirección del Secretario de Instrucción Pública. (1899). El Maestro de Escuela, revista escolar bimensual. Año 1. No 1 y 2, pp. 52-53.

Doctor del Valle, A. F. (1893). Higiene de la inteligencia. Revista de la Instrucción pública de Colombia. Año I, . I, p. 319.

Foucault, M. (1966). La arqueología del saber. México: Siglo XXI.

Gómez Anzola, G. H. (1935). La mujer y el hogar. Revista pedagógica. Órgano de la Escuela Normal de institutores. Año VIII. No. 4, pp. 126-1927.

Johonnot, J. (1893). Sección pedagógica, Pestalozzi. Revista de la Instrucción pública de Colombia. Año I, T. I, p. 276.
La obra de la mujer. Discurso de una señorita alumna dedicado por ella al señor Eustorijio Salgar. (1874). La Escuela Normal, periódico de Instrucción Pública. T. V, No. 202, p. 360.

Menéndez, R. (1894. ). La mujer Instruida. Revista de la Instrucción Pública de Colombia. T. III, p. 112.

Pardo Bazah, E. (1894). La Educación del hombre y de la mujer (Memoria leída en el congreso pedagógico, 16 de octubre de 1892). Revista de la Instrucción Pública de Colombia. Año 2, T. II., p. 286.

Quijano, M. S. (1999). La maestra en la educación en Colombia 1870-1890. En Vida de Maestro. El profe es una nota. Bogotá: IDEP.

Restrepo, M. M. (1916). Pedagogía doméstica. Capítulo III. La esposa. Revista de la Instrucción Pública de Colombia. T. XXVIII, p. 307.

Rodríguez, P. (1997). Sentimientos y vida familiar en el Nuevo Reino de Granada. Bogotá: Ariél.

Simón, J. (1983). Sección científica, de la influencia de la mujer y de su educación en las costumbres. Revista de la Instrucción Pública de Colombia. Año 1, T. II, pp. 427-429.

Vahos, L. (2002). Mujer y educación en la Nueva Granada. Bogotá: Comunicación creativa Ramírez. 


\section{Diálogo del conocimiento}

El documento, que ha sido desarrollado concretamente con el propósito de evidenciar las subjetividades otorgadas a lo femenino a finales del siglo XIX y comienzos del XX desde un aspecto educativo y pedagógico, muestra claramente los prejuicios sexistas y estereotipados que se han consolidado por años hacia las mujeres, lo cual repercute negativamente en la percepción y concepción de las mujeres y su entorno.

Ahora, es necesario resaltar que la apreciación sobre las mujeres, como se describe en el artículo, no proviene solo de los siglos comentados, pues recordemos que en el campo de la filosofía ya se hallaban, de forma arraigada, posturas sobre lo que debían aprender y hacer las mujeres. En el siglo XVIII, Rousseau afirmaba que la educación de las mujeres debía estar en función de la de los hombres, dirigida a agradarles, a ser útiles, de manera que los hombres las amaran y estimarán; dirigida a educar a los hombres cuando estaban pequeños y cuidarlos cuando crecieran. También, Santo Tomás aduce que la mujer fue creada solo para ayudar al hombre, pero en la procreación.

Y es que dicha asignación de roles, que se proclaman propios de las mujeres, ha terminado en la consecución y desarrollo de su inferioridad histórica y en una actitud masculina fundamentada en el poder y la represión hacia ellas.

A la actualidad como rezago de los conceptos desiguales y sexistas, se presenta la grave problemática de la violencia de género, que de forma sistemática, recurrente y basada en el género se configura como feminicidio, igualmente, se halla la diferencia laboral y salarial entre hombres y mujeres, la misoginia y la exclusión social,ejecutada no solo por los hombres sino por toda la sociedad en su conjunto, que violan los derechos de las mujeres.

En este mismo sentido, es relevante la posición, igualmente sexista y machista, que ha desarrollado la representación estatal, pues si bien es cierto que para el año de 1990 en Colombia se consideró a la mujeres como sujetas objeto de la agenda gubernamental, esta siempre ha estado dirigida a la protección de las mujeres en los campos que históricamente han sido asignados a las mujeres. Por ejemplo, el Legislador ha venido expidiendo normas destinadas a prevenir y erradicar toda forma de violencia en contra de las mujeres y lo ha hecho resaltando la violencia que padecen las mujeres en el ámbito familiar, por lo que la mayoría de leyes que sancionan las conductas delictivas en contra de los derechos de las mujeres se ubican en la violencia intrafamiliar.

Por su parte, las políticas públicas que encierran las discusiones políticas, la diferenciación de problemas y soluciones - articuladas a los partidos, grupos sociales y personas, bien sea que estén en el gobierno o en la oposición- han generado acciones y programas. Pero su estudio evidencia la tolerancia social a la violencia contra las mujeres ligada a los imaginarios culturales y al desconocimiento que aún tiene la gran mayoría de las mujeres sobre sus derechos y mecanismos de protección; visualiza a las mujeres en contextos del hogar, la familia, en su rol de madre, guardando los estereotipos que se le han adjudicado a las mujeres.

Finalmente, se puede percibir que la investigación realizada deja una gran reflexión para la comunidad académica sobre los retos necesarios para la transformación de una cultura desigual en función del género, que puede ser intervenida a partir de valiosas herramientas pedagógicas.

Nayibe Paola Jiménez Rodríguez 